\title{
La aportación de la biomasa al aprovechamiento energético
}

\author{
Ramón Martín Mateo \\ Catedrático de Derecho Administrativo \\ Universidad de Alicante
}

\section{UNA ENERGÍA AMBIENTALMENTE POSITIVA}

Como se ha anticipado el objeto principal de este estudio, es ofrecer soluciones para el incremento de las disponibilidades energéticas de la humanidad sin que con ello se incremente la contaminación atmosférica, especialmente en lo que respecta al $\mathrm{CO}_{2}$ y por tanto al efecto invernadero.

Posiblemente, a la postre, no habrá otra solución que la de la fusión nuclear, pero parece aconsejable que se ponderen antes otras alternativas mas asequibles y menos problemáticas.

Este es sin duda el caso del aprovechamiento de la biomasa que tiene de entrada unas características altamente positivas a los efectos de un estudio de posi-

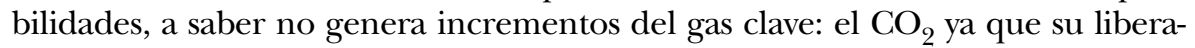
ción como consecuencia del aprovechamiento de la energía contenida en vegetales libera el mismo montante de $\mathrm{CO}_{2}$ que fue asimilado en su día por la planta de referencia, bien es verdad que en este razonamiento hay una notable falacia, sobre todo para las especies de larga duración, las circunstancias naturales de su aprovechamiento actual difieren sensiblemente de las de la época en que almacenó el carbono atmosférico, pero el desajuste temporal es infinitamente inferior al que obra para los combustibles fósiles, que han asimilado carbono fósil de hace millones de años por lo que el juego compensatorio no tiene lugar.

La aportación de la biomasa al aprovisionamiento energética de la humanidad tiene manifestaciones significativas: la primera de ella constituida por el fomento de la utilización y mantenimiento de sumideros que permiten absorber los gases que influyen en el recalentamiento del Planeta.

Esta estrategia prevista y recogida en los acuerdos de Kioto ha sido analizada por J. M. BALDASANO, uno de los más destacados expertos en la materia, tiene dos modalidades primordiales. 
Una de ellas consiste en el fomento y/o mantenimiento de los sumideros naturales especialmente de los existentes en países en desarrollo y otra en la financiación ex novo de biocomplejos de este tipo, los denominados mecanismos de desarrollo limpio que permiten en el contexto de la normativa de Kioto compensar estas iniciativas con las obligaciones de reducción de emisiones que afectan a sus financiadores de países industrializados.

Una dimensión, por tanto, singularmente positiva de este tipo de estrategias alternativas, es la consistente en la posibilidad de que por estas vías se fomente el desarrollo de complejos forestales de vocación, exclusiva o compartida, de índole maderera, con lo que además de retirarse $\mathrm{CO}_{2}$ se conseguiría estimular económicamente estas operaciones, al obtenerse importantes ingresos por la venta de las maderas obtenidas.

$\mathrm{El}$ aprovisionamiento de madera utilizable como alternativa a materiales metálicos cuya fabricación implicaría el empleo de elevados contingentes de materias primas y energía, supondría evitar el consumo de combustibles convencionales, generadores de gases invernadero, lo que afecta sobre todo a los materiales de construcción, un complejo importante en cuanto al consumo de materias primas, que precisan para su obtención y elaboración, el empleo de energías altamente contaminantes, tanto en la edificación como en relación con la recuperación energética, una vez agotada su vida funcional.

El desideratum en términos de balance positivo de estos mecanismos consistiría pues en la posibilidad no ya solo de garantizar la inocuidad de los subproductos generados, sino en el aprovechamiento positivo, energéticamente, de los residuos madereros y de las operaciones de cuidado y poda de los montes y de otros complejos naturales o artificiales equiparables, lo que supone ahorros muy estimables de combustibles fósiles.

\section{LA ALTERNATIVA BIOLÓGICA}

Recordemos que tras los orígenes cósmicos de nuestro planeta se propició la disponibilidad de la energía generada por un astro próximo el Sol. El agua basada en el hidrógeno disponible daría lugar a la vida, proceso este que presenta aún palmarias incógnitas, siendo la más significativa la relacionada con el protagonismo divino.

Pero lo que a otra escala mucho mas modesta aquí nos interesa, es recordar que como consecuencia de las circunstancias mencionadas, la reproducción de 
las especies que se difundieron por la superficie terrestre y los cataclismos cósmicos ulteriores, dieron lugar a que se enterraran componentes biológicos en medios que propiciaron su transformación en hidrocarburos, haciendo que estos fueran extraídos masivamente en nuestro periodo histórico, empleándolos masivamente como combustibles: sólidos y líquidos, lo que ya en nuestro días, como consecuencia de su masiva y prácticamente monopolística función, originó el efecto invernadero y el recalentamiento de la biosfera, que se intenta corregir.

La etapa postenergía fósil por la que ahora transitamos, plantea dos alternativas básicas: la opción por la energía nuclear, y la de las energías renovables, la primera basada en la física y la segunda en la biología.

Dejando de lado la problemática correspondiente a la energía nuclear cuyo análisis incorpora habitualmente componentes de naturaleza emocional y que desde luego no ofrece una solución inmediata a un problema que no puede aplazarse, analizaremos a continuación las características y circunstancias de las alternativas renovables y su viabilidad para atender las dos demandas mas importantes en estos momentos para la vida en la Tierra: la superación del efecto invernadero y el suministros de recursos energéticos suficientes para atender las necesidades de una población terráquea en expansión.

Ahora bien recordemos que una solución energética que fuese considerada como la más favorable para los intereses de la humanidad, no podría disociarse de la lógica energética global de la naturaleza, debiendo situarse en primer lugar la evitación del efecto invernadero ya que de poco valdría disponer de energía abundante y barata si la Tierra por el recalentamiento sucesivo de su atmósfera a la larga resultase inhabitable para nuestra especie, lo que nos hace considerar en primer lugar los dispositivos necesarios para impedirlo, que no son otros que los contemplados en las conclusiones de Kioto.

A) Estrategia para la reducción del carbono atmosférico.

El logro de los objetivos perseguidos por el importante acuerdo internacional de Kioto, está basado en dos estrategias perfectamente plausibles: a saber la reducción de las emisiones de $\mathrm{CO}_{2}$ en la fuente y la retirada del carbono albergado, más allá de los límites razonables, en la biosfera.

Al primer objetivo sirven las medidas limitatorias establecidas por los responsables del Convenio de Kioto: a saber órganos superiores de las Administraciones de las Partes: instituciones supranacionales o intermedias, como es entre nosotros la Unión Europea y los Estados Nacionales finalmente. 
Pero como no se parte de cero no basta con reducir para el futuro las emisiones globales es preciso extraer de la atmósfera contingentes de $\mathrm{CO}_{2}$ acumulados con exceso en las naciones industrializadas sobre todo, para lo que son de aplicación las previsiones del Convenio sobre mecanismos de Desarrollo Limpio que permiten a naciones industrializadas pactar con países en desarrollo la eliminación desde estos países de excesos de carbono localizables en los países avanzados, lo que es factible por el hecho de que la atmósfera es común sobre la base de que la exportación parcial de la solución al problema no elude las obligaciones de los países desarrollados de cumplir en casa con sus deberes, reduciendo en su territorio también las emisiones y procurando captar el exceso ya procurando captar el exceso ya producido ${ }^{1}$.

Parecen en este contexto perfectamente razonables las propuestas del Nobel de Economía J. STIGLITZ de compensar a los países en vías de desarrollo por proporcionar estos servicios, recibiendo a cambio ayudas derivadas de incentivos adecuados de mercado, en lo que es líder Costa Rica, como personalmente pude comprobar hace tiempo ${ }^{2}$.

Un caso extremadamente significativo es el de la Amazonia brasileña, seguramente el mayor sumidero real y sobre todo potencial del mundo, que pierde cada año buena parte de sus posibilidades como sumidero internacional.

España no está en condiciones de dar ejemplo al respecto, nuestro país ha perdido buena parte de su cubierta natural lo que deberá animar la implantación de un Plan extraordinario de recuperación de suelos y arbolado, teniendo en cuenta que la degradación de suelos afecta al $31 \%$ del territorio español, sin que hasta la fecha se haya aprobado el Plan que a instancia de las Naciones Unidas nos comprometíamos a adoptar ${ }^{3}$, siendo uno de los países industrializado donde mas aumentan las emisiones de $\mathrm{CO}_{2}$ que se han incrementado un $45,61 \%$ en 2004 respecto a 1990 .

\footnotetext{
${ }^{1}$ Sobre estos temas me remito a las fundamentales aportaciones de J. M. BALDASANO, perteneciente al reputado equipo de vigilantes del clima de las Naciones Unidas, que ha colaborado decisivamente en la redacción del estudio Cambio Climático y Necesidades Energéticas, Capítulo 4 de Estrategias Mediterráneas del Desarrollo Sostenible. Fundación Jaime I, Valencia 2003.

${ }^{2}$ Vid J. E. STIGLITZ "Por un crecimiento económico limpio", en El País 21 de Junio 2005.

${ }^{3}$ M. BAYÓN, “La lucha contra la desertización”, 17 de junio de 2005.
} 
A escala mundial el proceso obviamente es todavía mas alarmante estimaciones de las Naciones Unidas cifran en 135 millones de personas las que deberán abandonar por estas causas sus lugares de origen ${ }^{4}$.

B) Los biocombustibles.

Hemos explorado hasta la fecha la posibilidad de que los bosques y los árboles en general puedan funcionar como asimiladores del carbono sustrayendo este a los mecanismos productores del efecto invernadero.

Efectivamente existen evidencias científicas y prácticas de tales virtualidades, constituyendo el manejo de las masas vegetales un instrumento apto para coadyuvar eficazmente en una estrategia que impida que el recalentamiento de la atmósfera de nuestro planeta pueda producirse o al menos paliándolo.

Ahora bien estos mecanismos tienen un límite importante, si bien no inmediato, el decaimiento de la vida de los conjuntos forestales, lo que puede evitarse con la reforestación y el impulso del mercado ordinario de la madera pero aún sin ello con la posibilidad de emplear los productos forestales para la generación directa de energía y sobre todo mediante la obtención de combustibles, que constituyan un sustitutivo de las energías fósiles convencionales o un complemento de las mismas, si bien la obtención de los denominados biofueles puede y debe además realizarse a través del empleo, como materia prima, de plantas no madereras.

Si este tipo de combustibles pudieran atender si no a toda, a una parte sustancial de la demanda energética, habríamos "rizado el rizo" de la eficiencia energética-ambiental, de la Humanidad ya que sin generar efecto invernadero, al absorberse $\mathrm{CO}_{2}$ dispondríamos de la energía solar almacenada vía fotosíntesis para aplicarla a la producción de bienes económicamente valorables y apreciables.

En este sentido se ha observado que los bosques: además de su conocida función como sumideros de carbono ofrecen productos "que aparte de fijar carbono durante su mayor o menor vida, ahorran la energía que requiere la fabricación de productos sustitutivos que compiten con la madera en las aplicaciones de consumo, como pueden ser los metales, plásticos, cemento, etc". Además de lo cual y esto es lo mas importante, en cuanto que suponen una

\footnotetext{
${ }^{4}$ S. POZZI, El País, 17 de junio 2005.
} 
fuente de combustible basada en "carbono" previamente extraído de la atmósfera, equilibran el balance energético y evitan el empleo de carbono fósil en forma de hidrocarburo ${ }^{5}$. Coloquialmente podríamos decir que es el Sol el que paga, mediante la fotosíntesis que realizan las plantas a sus expensas, los costos precisos para el ulterior aprovechamiento de la madera, lo que explica la rentabilidad neta del fomento de ampliaciones forestales.

Debe resaltarse en esta dirección la excelente aportación doctrinal de A. José SÁNCHEZ SÁEZ, profesor de la Facultad de de Derecho de Sevilla, sobre las demandas de suelo derivadas del desarrollo de la biomasa como fuente de energía renovable ${ }^{6}$ que constituye el trabajo más valioso que se ha aportado desde la "ingeniería social" a este importante tema que abre las puertas a una amplia difusión de las tecnologías propias de los biocarburantes, con un ritmo esperanzador, lo que patentiza su inclusión en el Primer Plan de Fomento de la Energía Renovable aprobado por el Consejo de Ministros el 30 de Diciembre de 1999 elaborado por el Instituto para la Diversificación de la Energía, que considera que las materias primas mas importantes este respecto son:

- Las semillas oleaginosas; colza, girasol, linaza y soja entre otras cuyos aceites pueden transformarse en el biodiésel al que más adelante nos referiremos.

- Plantas amiláceas; trigo, maíz, remolacha, etc., materias primas para la síntesis del bioetanol alternativo de la gasolina.

- Plantas lignocelulósicas; utilizadas para procesos de maderas de escasa calidad, especialmente las de crecimiento rápido que pueden dar lugar a biocombustibles o por lo menos a alimentar procesos de combustión utilizables para generar electricidad.

C) El biodiésel como objetivo final.

Es indudable que el aprovechamiento energético y la protección del ambiente habrían prosperado espectacularmente, si los combustibles fósiles que

\footnotetext{
${ }^{5}$ Me remito a la excelente aportación al tema realizado por E. VALERO GUTIÉRREZ DEL OLMO, "Los bosques como sumideros del carbono una necesidad para cumplir con el Protocolo de Kioto", Director del Grupo de Investigación AF-4 de la EUIT Forestal de Pontevedra, Universidad de Vigo.

${ }^{6} \mathrm{El}$ potencial de la biomasa como fuente de energía renovable.
} 
hoy monopolizan sin discriminación alguna al respecto, el abastecimiento del medio mas difundido de transporte, el automóvil individual, pudieran ser sustituidos por combustibles de origen orgánico inmediato, no diferido como es el caso de las gasolinas, que han debido esperar siglos para su aparición, se trata pues de acelerar el proceso, aunque desde luego en términos inicialmente muy inmediatos.

Este tipo de carburantes requerirán para su obtención en gran escala el cultivo y explotación de plantas de las características mencionadas por A. J. SÁNCHEZ SÁEZ en su meritoria investigación citada, que pertenecen bien al acerbo de los cultivos agrícolas tradicionales de secano en España y en Europa caso de los cereales y de ciertas especies de regadío como la remolacha y por supuesto de semillas oleaginosas que dan lugar a aceites constitutivos de la materia prima empleando básicamente en la obtención del gasoil.

Hay que decir, que a escala prácticamente artesanal se han dado ya pasos en este sentido auspiciado incluso en la Universidad de Alicante desde mi Departamento siguiendo, las pautas de Cataluña donde mas se ha avanzado en España en una dirección, en la que ya habían prosperado otros países europeos, utilizándose como materia prima grasas vegetales y aceites usados en la industria y sobre todo en la hostelería.

A la planta de Stoks del Vallés se han sumado la de Biohor en Álava y otro de Bionet en Reus. El Plan de Energía de Cataluña prevé que en el 2010 el 8\% al menos de los automóviles utilicen este combustible.

Debe recordarse que estos procesos como todos los que utilizan recursos de origen agrícola no restan en el balance energético global, ya que el $\mathrm{CO}_{2}$ producido equivale al retirado en la etapa de producción de las plantas que le respaldan. Por lo demás no se trata de algo revolucionario e insólito ya que desde hace muchos años se viene comercializando el aceite de girasol y el de colza que tuvieron su auge en los lejanos tiempos de la autarquía con fines alimenticios y de la posguerra, si bien últimamente al no contarse para estos cultivos con apoyos sustanciales de Bruselas y carecer además este tipo de aceites del favor de los consumidores que el de girasol que sigue teniendo, en Castilla al menos, una cierta implantación no pasa por sus mejores momentos.

Es de esperar que cambie esta situación en el futuro a medida que se progrese en la corrección del cambio climático, teniendo en cuenta que al menos el aceite de colza y el de girasol están al borde de la rentabilidad y con un pequeño impulso de Bruselas o Madrid podrían expandirse en el campo espa- 
ñol, según recuerda SÁNCHEZ SÁEZ una hectárea de colza produce anualmente 940 kilos de aceite equivalente a 1.090 litros de biodiésel y la de girasol 600 kilos de aceite o 700 litros de biodiésel ${ }^{7}$.

Lo que ahora se pretende para mantener las condiciones vitales de la Biosfera, no es solamente potenciar el funcionamiento de sumideros naturales de los gases de invernadero, caso prototípico de los bosques, si no considerar estas y otras instancias como productores potenciales de energías renovables, lo que también asume indirectamente el Protocolo de Kioto y explícitamente la Unión Europea.

La Directiva 2003/30/CE de 8 de mayo "aconseja que el $2 \%$ de toda la gasolina y el gasoil que consume el transporte por carretera de la U.E. sea sustituido por biocarburantes antes del 31 de diciembre de 2005".

El Libro Blanco de la Comisión Europea aprobado por la Comisión Europea 1997/599 establecía que en el año 2010 el 12\% del consumo interior bruto de energía deberá ser abastecido por fuentes de energías renovables.

Es clave en esta materia la Directiva 2003/30/CE del Parlamente Europeo sobre fomento del uso de biocarburantes y otros combustibles renovables en el transporte, que obliga a los Estados a velar porque se comercialice en sus mercados una proporción mínima de biocarburantes y de otros combustibles renovables.

La Comisión, ha propugnado también en el 2002 una estrategia temática sobre protección del suelo. En España el Plan de Fomento de las Energías Renovables consideró que la energía de la biomasa es la que mayores posibilidades tiene dentro de este contexto ${ }^{8}$.

El Plan Forestal Español aprobado por el Consejo el 5 de julio de 2002, una norma de muy pobre ambición técnica que intentó aplicar la escasamente moderna Estrategia Forestal Española de 1998, pretende conseguir, lo que parece laudable, aunque no se den las pautas necesarias para ello, la utiliza-

${ }^{7}$ Según A. J. SÁNCHEZ SÁEZ, cit. Pág. 7.

${ }^{8}$ Aprobado por acuerdo del Consejo de Ministros de 30 de diciembre de 1999, el Plan incluye a los residuos domésticos de aceite de frituras que particularmente en el contexto de los residuos de establecimientos de restauración, está jugando un original papel en el fomento del biodiésel. 
ción de los bosques como sumideros y el aprovechamiento de la biomasa de los residuos forestales, algo desde luego positivo pero que no supondría espectaculares progresos energéticos.

Lo que realmente se espera de los bosques, y sobre todo de los cultivos ad hoc, de acuerdo con los auténticos dictados de la dinámica energética contemporánea, es su aportación a la sustitución de las energías negativas en términos ambientales favoreciéndose el incremento de las disponibilidades energéticas menos contaminantes, con capacidad, parcialmente al menos, sustitutoria o complementaria de las aportaciones clásicas de soporte fósil.

En este sentido es sin duda positivo que la Unión Europea haya apostado por la alternativa aquí comentada promulgando la Directiva citada 2003/30/CE de 8 de mayo de 2003 relativa al Fomento del uso de biocarburantes y otros combustibles renovables en el transporte, de 8 de mayo de 2003, en cuanto que ello puede contribuir además a la reducción de la dependencia de las importaciones energéticas y de las emisiones de gases de efecto invernadero.

La Directiva citada considera biocarburante el combustible líquido o gaseoso producido a partir de la biomasa y de la fracción biodegradable de los productos, desechos y residuos procedentes de la agricultura y de la selvicultura, incluidas las substancias de origen vegetal y animal de la silvicultura y de industrias conexas así como la fracción biodegradable de los residuos industriales y municipales ${ }^{9}$. Prudentemente el Parlamento Europeo y el Consejo promulgadores de la Directiva en cuestión, señalan en la Exposición de Motivos de la Directiva reseñada, argumentan que "El fomento de la producción y el uso de biocarburantes podrían contribuir a la reducción de la dependencia de las importaciones energéticas y de las emisiones de efecto invernadero".

Uno de los factores más significativos para la obtención de los biocarburantes es la disponibilidad de aceites vegetales nuevos, obtenidos de las plantas oleaginosas ya citadas, para lo que podrían utilizar baldíos o áreas erosionadas que aunque no disponen de un suelo adecuado puede ser reproducido o regenerado con apoyo a los materiales orgánicos obtenidos de la gestión de los residuos municipales, siempre y cuando se disponga del agua necesaria, para lo cual deberá implantarse una estrategia ad hoc, tanto en los servicios municipales de recogida y tratamiento de residuos sólidos, como en la disposición

\footnotetext{
${ }^{9}$ Artículo 2.1.
} 
de las aguas residuales municipales, obviamente mediante tratamientos preventivos que garanticen la viabilidad sanitaria de la operación.

Otros proyectos que abordan estas posibilidades que debo reconocer que no han suscitado un particular entusiasmo ni en los medios municipales ni en los de gestión de lo forestal mas apegados a rutinas y tradiciones que se compaginan mal con estas nada románticas propuestas, aunque sigo recordando con todos los respetos debidos al bucolismo, que lo que tenemos entre manos es la salud del Plantea, que en alguna medida puede mejorarse si conseguimos vía fotosíntesis retirar carbono de la atmósfera y además producir energías limpias que reemplacen a las generadas por la actual utilización en exclusiva de los combustibles fósiles, intento que traslada el testigo en buena medida a las autoridades municipales.

Por supuesto es preciso también la responsabilización del sector público en la ordenación del sector forestal función que desde la creación de la Administración moderna viene desempeñando, pero ahora deberá además recabarse y orientarse la actuación municipal para que coordinadamente desde estas estancias, se adopte una política de gestión de residuos sólidos y líquidos que facilite el establecimiento de un sistema ecológico-productivo que apoye la utilización al respecto de energías auxiliares renovables, compatibilizadoras del disfrute actual de los terrícolas de su patrimonio forestal por las generaciones venideras.

Durante el verano del 2005 en que redacté este trabajo leo en la prensa una serie de mensajes poco tranquilizadores, que decían así:

El desierto avanza sobre el Planeta.

La ONU calcula que la desertificación forzará a 135 millones de personas a abandonar su hogar.

Greenpace afirma que el cambio climático es el mayor problema y tacha a EE.UU. de egoísta.

La degradación del suelo afecta al $31 \%$ del territorio español.

La Amazonia pierde una extensión similar a la de Galicia en un año.

España es el país industrializado donde mas aumentan las emisiones de $\mathrm{CO}_{2}$.

Una batalla costera por aprovechar el poder del viento. 


\section{Los biocarburantes esperan su oportunidad.}

El consumo de combustibles limpios en el sector del transporte apenas llega al 1\% de total.

Las energías renovables solo cubren el 2\% del objetivo fijado para 2010.

Las energías renovables solo cubren el 28\% del objetivo fijado para 2010.

Un carácter meramente anecdótico en relación con el tema del biodiésel que nos ocupa, pero que puede ser significativo a la larga es el titular que alude a La sorpresa del biodiésel informando que la única planta de producción en el Vallés, se unirá pronto otra de Bionor en Álava y de Bionet en Reus.

\section{LA BIOMASA EN EL PLAN DE ENERGÍAS RENOVABLES DE ES- PAÑA, 2005-2010}

Entre los objetivos 2010 el Plan, dentro de área de biocarburantes fijó el objetivo de alcanzar los 500.000 tep a finales del año 2010 partiendo de una situación de referencia de total ausencia de plantas de producción de biocarburantes.

En la situación actual, con el 45,6\% del objetivo del Plan cumplido y un sector industrial en plena expansión, y tras la aprobación de la Directiva 2003/30, que recoge el objetivo de cubrir el $5,75 \%$ de la cuota de mercado de combustibles para el transporte con biocarburantes y otros combustibles renovables, es preciso ampliar el escenario de desarrollo del sector para los próximos años asumiendo los objetivos recogidos en la Directiva 2003/30, lo que elevaría el objetivo energético para el sector en el horizonte de 2010 hasta alcanzar los 2,2 millones de tep.

\section{CONCLUSIONES}

El Plan 2005-2010 realiza según sus redactores, la revisión del Plan de Fomento de las Energías Renovables en España 2000-2010 ${ }^{10}$ hasta ahora vigen-

\footnotetext{
${ }^{10}$ Aprobado por acuerdo del Consejo de Ministros el 30 de diciembre de 1999.
} 
te. Con esta revisión, se trata de mantener el compromiso de cubrir con fuentes renovables al menos el $12 \%$ del consumo total de energía en 2010, objetivo que informa las políticas de fomento de las energías renovables en la Unión Europea desde la aprobación del Libro Blanco ${ }^{11}$ en 1997, y que en España fue establecido por la Ley del Sector Eléctrico ${ }^{12}$ y dio lugar al mencionado Plan de Fomento. Asimismo, este PER 2005-2010 incorpora los otros dos objetivos indicativos para el año $2010-29,4 \%$ de generación eléctrica con renovables y $5,75 \%$ de biocarburantes en transporte- adoptados con posterioridad al anterior plan.

De acuerdo con el Plan citado "el consumo de biocarburantes en España ascendió a finales de 2004 a 228,2 ktep. La relevancia de este dato se encuentra en el hecho de que, hasta el año 2000 no existía ninguna planta de producción de biocarburantes en funcionamiento, mientras que a finales de 2004 nuestro país ya era el líder europeo en la producción de bioetanol y había experimentado un rápido avance en el sector del biodiésel".

Pero más que los valores absolutos, que nos muestran que a finales de 2004 ya se había completado el 45,6\% del objetivo energético que fijó el Plan de Fomento para esta área en el horizonte de 2010, lo importante en este sector es la tendencia de crecimiento en la que se encuentra, que dibuja un escenario de expansión francamente optimista. El reflejo del mismo se encuentra en una figura, en la que se observa perfectamente la evolución del sector durante los últimos años.

En cuanto a los objetivos 2010 del mencionado Plan se destaca alcanzar los 500.000 tep a finales del año 2010 partiendo de una situación de referencia de total ausencia de plantas de producción de biocarburantes.

En una situación ulterior, con el 45,6\% del objetivo del Plan cumplido y un sector industrial en plena expansión, y tras la aprobación de la Directiva 2003/30, que recoge el objetivo de cubrir el $5,75 \%$ de la cuota de mercado de combustibles para el transporte con biocarburantes y otros combustibles renovables, es preciso ampliar el escenario de desarrollo del sector para los pró-

11 Comunicación de la Comisión: Energía para el futuro: Fuentes de Energía Renovables. Libro Blanco para una Estrategia y un Plan de Acción Comunitarios (Documento COM (97) 599 final). Bruselas, 26/11/97.

${ }^{12}$ Ley 54/1997, de 27 de noviembre, del Sector Eléctrico. 
ximos años asumiendo los objetivos recogidos en la Directiva 2003/30, lo que elevaría el listón energético para el sector en el horizonte de 2010 hasta alcanzar los 2,2 millones de tep.

Según R. MENÉNDEZ ${ }^{13}$ España debería multiplicar por 10 el uso de carburantes ecológicos antes de cinco años. La Comisión de la Energía pide al Gobierno que recicle el aceite de fritura usado en biodiésel. Los carburantes ecológicos, obtenidos a partir de plantas como el girasol o la remolacha, no terminan de arrancar en España. La Comisión Nacional de la Energía (CNE) estudia un informe sobre el biodiésel y el etanol que pretende lograr que en 2010 el 5,75\% de los carburantes sean ecológicos habría que multiplicar por 10 el consumo actual, algo difícil de alcanzar.

El informe de la Comisión Nacional de la Energía sobre los biocombustibles señala que la producción de estos carburantes "puede suponer una alternativa interesante para aquellas tierras agrícolas que como resultado de la Política Agraria Común queden abandonadas", algo que "permitiría mantener los niveles de renta y trabajo".

${ }^{13}$ El País, 2 de noviembre de 2005, pág. 31. 